\title{
10 \\ THE CONSEQUENCES OF CLIMATE CHANGE ON VULNERABLE POPULATIONS
}

\author{
Richa Sharma and R. Srikanth
}

\section{Introduction}

Humankind's heavy dependence on fossil fuels, deforestation, industrialisation, lifestyle changes, etc., have resulted in global warming. While the impact of climate change is felt across all geographies and populations, it is evident that some groups and communities are particularly vulnerable, with these impacts affecting them disproportionately (Islam \& Winkel, 2017). Least developed nations, small island countries, coastal region communities, etc. are more susceptible, as are women, children, elderly, those with low income or vulnerable occupational groups. This chapter gives an overview of the topic by:

1. Introducing the concepts of vulnerability including exposure, sensitivity and adaptivity in terms of climate change health impacts and risks.

2. Describing the importance of understanding and mapping vulnerability with a focus on the most vulnerable populations by age, gender, health condition and socio-economic factors.

3. Discussing the various determinants of vulnerability from the perspectives of policymakers and healthcare professionals.

\section{The concept of vulnerability}

Vulnerability is defined as an exposed system's or subject's internal risk factor corresponding to its intrinsic propensity or predisposition to be adversely affected by the hazard (Cardona, 2004; IPCC, 2014). In a public health context, vulnerability to climate change is defined as the degree to which individuals or communities are prone to the health impacts of climate change.

The Sendai Framework (UNISDR, 2015) defines vulnerability as the conditions determined by "physical, social, economic and environmental factors or processes, which increase the susceptibility of a community to the 
impact of hazards." This definition of vulnerability is in close alignment with the World Health Organization's (WHO) definition of the social determinants of health as the "circumstances in which people are born, grow up, live, work and age, and the systems put in place to deal with illness." These circumstances, in turn, are influenced by the distribution of money, power and resources at international, national and local levels.

Vulnerability is dynamic, varies across temporal and spatial scales, and depends on various determinants such as economic, social, geographic, demographic, cultural, institutional, governance and environmental factors. An essential step for working on adaptation plans is the assessment of vulnerability to climate variability and extremes. Understanding the climate change vulnerabilities, and especially those of the most vulnerable population, is important for policymakers, state/city development authorities, social service providers, etc. who are required to respond to the health impacts of climate change. Their vulnerability assessments should collectively consider how populations of concern experience disproportionate, multiple, and complex risks to their health and well-being in response to climate change.

Vulnerability can be assessed using the Vulnerability framework (Turner, et al., 2003), which is built on three factors, viz. exposure, sensitivity and adaptive capacity. Exposure is determined by the presence of the people in hazard zones and being subject to potential health losses. Higher exposure contributes to increased vulnerability. For instance, construction and agricultural labourers, who work outdoors in the sun, have a higher vulnerability to extreme heat due to their increased exposure. Sensitivity is the degree to which an individual or a system is affected by climate-related stimuli. Sensitivity is often determined by factors including underlying health conditions, medical issues, age, gender, disabilities (physical, mental, cognitive, or sensory), etc. Adaptive capacity is the ability of communities, institutions, or people to adjust to potential hazards or to respond to the consequences of the same.

Vulnerability assessments help in identifying and implementing the appropriate mitigative and adaptive measures for the most vulnerable population. Some of the climate-sensitive health vulnerabilities include extreme temperature, extreme weather, UV radiation, vector-borne diseases, food and water safety, and security, and air quality, to mention a few.

Specific groups of people are at higher risk for distress and other adverse mental health consequences from exposure to climate-related or weatherrelated disasters. These groups include children, the elderly, women (especially pregnant and post-partum women), people with disabilities, people with pre-existing mental illness, the economically disadvantaged, the homeless and first-responders. Communities that rely on the local environment for their livelihood, as well as populations living in areas that are more prone to specific climate change events, are at increased risk for adverse mental health outcomes. 


\section{The health impacts and vulnerabilities of vulnerable populations}

\section{Women}

Women are more vulnerable to the impacts of climate because of their biological sex and the social structures and inequalities, especially in developing and least developed nations. Physical and psychological health risks increase women's health-related vulnerabilities to climate change. This can further impact reproductive outcomes such as early pregnancy loss, stillbirth, premature delivery, perianal rashes and urinary tract infections. These may lead to greater mortality rates in comparison to men, higher rates of malnutrition, and increased exposure to sexual exploitation due to displacement resulting from events of extreme weather. Natural disasters affect the poor disproportionately. This is indicated by the fact that a large number of fatalities during major disasters occur in low- and middle-income countries, where death rates of women and children during a disaster are 14 times higher than that of men (Fatema et al., 2019).

Gender-specific attributes such as socially determined roles and responsibilities, such as women sacrificing their food for other family members, also impact the vulnerability of women. In developing countries, the higher vulnerability of women to the health impacts of climate change are also due to lack of shelter, use of fuel for cooking, and lack of access to food and safe water, resulting in issues with maintaining hygiene. Social inequalities and relatively lower formal education (as compared to men) amongst others, shape women's illness and their options for medical care. Women, especially in many developing and least developed nations, have lower social and economic power. Since they are limited by the lack of education and employment opportunities, they bear the higher burden of unpaid work related to family care and community activities. Such inequalities decrease the adaptive capacities of women while increasing their exposure and sensitivities, making them more vulnerable to the health impacts of climate change. Their vulnerabilities are further discussed in the chapter titled Gendered Vulnerabilities and Health Inequities.

\section{Children}

Children are one of the most vulnerable groups to climate change, owing to their biological modalities (such as high respiratory and metabolic rates, developing physiology, unique exposure pathways, limited adaptive capacities, etc.); they exhibit higher sensitivity to the various climate risks and threats. This is especially true in developing nations where climate change is expected to hit the hardest, and where safety nets are already compromised (King \& Harrington, 2018). Their vulnerability is further increased by their dependency on others (parents or caretakers), which compromises their adaptive capacity. Especially in the context of developing countries like 
India, children belonging to economically poor sections of society have the additional responsibility of taking care of their younger siblings, while parents are away as daily wage workers. Climatic conditions during the inutero stage affect the height and weight of foetuses, indicating that climate change can influence children's health and development even before they are born (Lokshin \& Radyakin, 2012). Climate change has also been found to negatively impact the cognitive performance of children (UNICEF, 2015). A 2019 Lancet report states that a child born today will experience a world that is more than four degrees warmer than the pre-industrial average, and that across the world, children are the worst affected by climate change (Watts et al., 2019). Due to various physiological and biological reasons, children are more vulnerable to impacts of degraded air quality (respiratory diseases like asthma, impacted lung development, etc.,), from floods including water-borne diseases (such as diarrhoea, respiratory, skin and eye diseases) and vector-transmitted diseases (such as dengue, chikungunya, and Zika, and zoonoses such as leptospirosis). It is also seen that exposure to traumatic events can impact children's ability to regulate emotions, impedes their cognitive development and academic performance and can contribute to post-traumatic stress disorder (PTSD) and other psychiatric disorders (such as depression, anxiety, phobia and panic). Children's ability to cope with disasters is affected by factors such as their socioeconomic status, available support systems and timeliness of treatment. Negative mental health effects in children, if untreated, can extend into adulthood.

Flooding-induced prenatal maternal stress influences the cognitive functioning of toddlers (Laplante et al., 2018; McLean et al., 2018; Moss et al., 2018), causing distress, anxiety and disillusionment in children (Mort et al., 2018), results in Post-Traumatic Stress Syndrome (PTSS) (Dogan-Ates, 2010) and also increases risks of pre-term births (Yu et al., 2018) which can cause neonatal morbidity, chronic health conditions and developmental disabilities with lifelong consequences. Extreme weather events like droughts and heat waves which impact crop production can also impact the maintenance of a satisfactory standard of public health in India where there is a high degree $(\sim 47 \%)$ of malnutrition especially among the children (Singh \& Dhiman, 2012).

\section{The elderly}

The decrease in the mobility of the elderly resulting from age, changes in physiology and more restricted access to resources limits the adaptive capacity of older people, putting them at greater risk of bearing the health impacts of climate change. For instance, older people are more vulnerable to temperature extremes and exhibit a significantly higher mortality risk in such extreme weather events. The elderly are also more susceptible to diseases and to the effects of stresses on food and water supply, compounded by the reduced ability to mobilise quickly. This further increases their 
vulnerability to climate change impacts. In addition to biological vulnerabilities, elderly people also experience socio-economic vulnerabilities. They might have been earning members earlier and are now possibly facing the dire consequences of abandonment due to the loss of negotiating power. Thus, the health effects of climate change on older people could be either due to the greater exposure of older people to the threat, those that decrease their adaptive capacity due to a combination of exposure plus greater reactivity as a characteristic of ageing (increased physiological susceptibility) or social factors that vary across individuals (social vulnerability). Therefore, several societal strategies will be required to enable the elderly to cope with the health effects of climate change.

\section{Persons with disabilities}

People with disabilities can experience disproportionate impacts of climate change unless the adaptation and response plans specifically take them into consideration. For example, risk-related communications do not necessarily target communication for individuals who are deaf, visually impaired, and those with low cognitive skills. Furthermore, they are caught in the povertydisability cycle and are vulnerable on several fronts. They are affected further due to inaccessible evacuation, response (including shelters, camps and food distribution), and recovery efforts. Most calamities have shown that that people with disabilities are most likely to be left behind, due to a lack of planning and inaccessible systems. Refugee camps or shelters are, in most cases, are not usually well-equipped to take care of their medical requirements. Therefore, climate change calamities that result in disruption to physical, social, economic and environmental networks and support systems, affect persons with disabilities much more than the general population (Box 10.1).

\section{Box 10.1 Case study}

"A disaster involves steps and procedures - information and warnings, timely evacuations, temporary safe settlements and rehabilitation. In each of these, Persons with Disabilities (PWD) and their needs remain unaddressed. Start with training manuals, camps and alarm systems: they need to be made available in accessible formats. During evacuation, their additional needs and assistive devices need to be picked up because without them, PWDs could become totally immobile. Then the struggle for food and basic amenities: it's not possible for us to stand in line for food. Moreover, rehabilitation for PWD requires a complete restoration of their "spaces". They had adapted 
themselves to a particular system and set-up, making it very difficult for them to adjust to a new one that may not be that considerate of their special needs. And what happens to people with psychological disabilities, those living in institutions, mental asylums or kept tied to beds? They are left behind. It's truly horrific. They are left without food, water or caretakers for days. There isn't much information about what happens to these people."

- Shivani Gupta, founder of cross-disability consultancy AccessAbility

Source: Chadha, 2020.

\section{Outdoor workers}

Climate change is expected to affect the health of outdoor workers due to their increased exposure to extreme weather conditions and low adaptive capacity. The outdoor workers experience adverse health effects of elevated temperature, in combination with changes in precipitation patterns, climate extremes and the effects of air pollution, which have a potential impact on their safety and well-being. Outdoor workers include farmers, agricultural workers, fishermen, construction workers, transportation-related workers, migrants and day wage labourers amongst others. With high heat and humidity, labour productivity for outdoor work drops as workers feel fatigued and need to take longer and more frequent breaks. With extreme heatwave conditions, workers report increased tiredness and exhaustion, dizziness, nausea, loss of appetite, musculoskeletal pain (triggered by the loss of body salts from excessive sweating) and fainting spells. Exposure to direct solar radiation may even blur the vision, impair judgment and make workers light-headed and irritable.

As a developing country with vast inequalities and a growing population that will age as the impacts of climate change become more severe over the next 30 years, India will have to have to be more prepared to take care of the health impacts of climate change through prevention and control measures. The Indian Government has been working with the States in this regard. During the National Review Meeting of the State Plans on Climate Change and Human Health held on December 17, 2019, almost all the States participated in the review meeting of State Plans on Climate Change and Human Health, and a cohort of 16 institutions was established under the initiative to serve as centres of excellence for climate change and health. More details on this topic can be seen in the chapter titled The Climate Change Policy 
Framework and Allied Programs in India. The promises of the developed countries during the Paris Agreement also remain largely unfulfilled since the total amount of pledges to the Green Climate Fund announced till May 12,2020 , is only USD 10.32 billion against the target collection of USD 100 billion every year by 2020 . Therefore, there is an urgent need to take concrete action to identify and mitigate the health impacts of climate change for the vulnerable groups identified in this chapter.

\section{Key takeaways}

- Vulnerability is the extent or degree to which a particular group is prone to the health impacts of climate change

- Vulnerability assessments are extremely beneficial in the context of climate change health impacts and risks.

- Certain groups are disproportionately affected; the vulnerabilities of women, children, the elderly, persons with disabilities and outdoor workers are described.

\section{References}

Cardona, O. (2004). The need for rethinking the concepts of vulnerability and risk from a holistic perspective: A necessary review and criticism for effective risk management. In Mapping vulnerability: Disasters, development and people (3751). Earthscan Publishers.

Chadha, S. (2020 Dec 03). Neglecting the Ones Most Affected: Climate Change and Disability. Bloomberg Quint. https://fit.thequint.com/health-news/why-the-climatemovement-needs-to-be-disability-inclusive

Dogan-Ates, A. (2010). Developmental differences in children's and adolescents'postdisaster reactions. Issues in Mental Health Nursing, 31(7), 470-476. doi: 10.3109/01612840903582528. PMID: 20521917.

Fatema, S., Islam, M., East, L. \& Usher, M. (2019). Women's health-related vulnerabilities in natural disasters: A systematic review protocol. BMJ Open, 9(12), e032079. doi: 10.1136/bmjopen-2019-032079

IPCC. (2014). Climate change 2014: Synthesis report. Contribution of working groups I, II, and III to the fifth assessment report of the intergovernmental panel on climate change, IPCC.

Islam, N. \& Winkel, J. (2017). Climate change and social inequality. UN DESA.

King, A. \& Harrington, L. (2018). The inequality of climate change from 1.5 to $2^{\circ} \mathrm{C}$ of global warming. Geographical Research Letters, 45(10), 5030-5033. doi: 10.1029/2018GL078430

Laplante, D., Hart, K. J., O’Hara, M. W., Brunet, A., \& King, S. (2018). Prenatal maternal stress is associated with toddler cognitive functioning: The Iowa flood study. Early Human Development, 116, 84-92. ISSN 0378-3782. doi: 10.1016/j. earlhumdev.2017.11.012

Lokshin, M., \& Radyakin, S. (2012). Month of birth and children's health in India. The Journal of Human Resources Winter, 47(1), 174-203. doi: 10.3368/jhr.47.1.174 
McLean, M., Cobham, V. E., Simcock, G., Elgbeili, G., Kildea, S., \& King, S. (2018). The role of prenatal maternal stress in the development of childhood anxiety symptomatology: The QF2011 Queensland flood study. Development and Psychopathology, 30(3), 995-1007. doi: 10.1017/S0954579418000408

Mort, M., Walker, M., Williams, A. L., \& Bingley, A. (2018). Displacement: Critical insights from flood-affected children. Health and Place, 52, 148-154. ISSN 13538292, doi: 10.1016/j.healthplace.2018.05.006

Moss, K., Simcock, G., Cobham, V. E., Kildea, S., Laplante, D. P., \& King, S. (2018). Continuous, emerging, and dissipating associations between prenatal maternal stress and child cognitive and motor development: The QF2011 Queensland flood study. Early Human Development, 119, 29-37.

Singh, P. \& Dhiman, R. (2012). Climate change and human health: Indian context. Journal of Vector-Borne Diseases, 49, 55-60.

Turner, B., Kasperson, R. E., Matson, P. A., McCarthy, J. J., Corell, R. W., Christensen, L., ... \& Schiller, A. (2003). A framework for vulnerability analysis in sustainability science. Proceedings of the National Academy of Sciences, 100(14), 80748079. doi: 10.1073/pnas.1231335100

UNICEF. (2015). Unless we act now: The impact of climate change on children. UNICEF.

UNISDR. (2015). Sendai framework for disaster risk reduction 2015-2030. UN.

USGCRP. (2016). The impacts of climate change on buman health in the United States: A scientific assessment. U.S. Global Change Research Program.

Watts, N., Amann, M., Arnell, N., et al. (2019). The 2019 report of the Lancet countdown on health and climate change: Ensuring that the health of a child born today is not defined by a changing climate. The Lancet, 394(10211), 1836-1878. doi: 10.1016/S0140-6736(19)32596-6

Yu, X., Feric, Z., Cordero, J. F., Meeker, J. D., \& Alshawabkeh, A. (2018). Potential influence of temperature and precipitation on preterm birth rate in Puerto Rico. Scientific Reports, 8, 16106. 